\title{
Teaching Anthropology
}

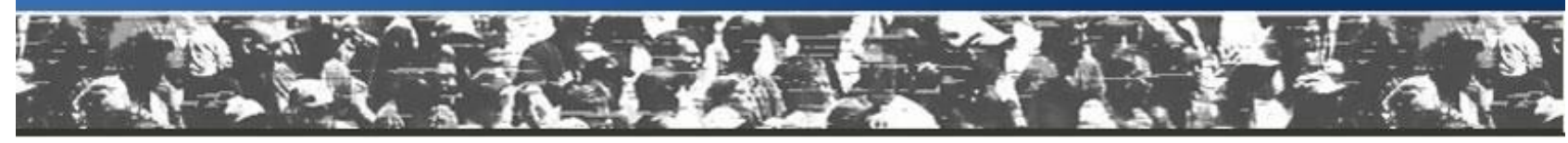

\section{Reading While Walking: A Reflection on Interdisciplinary Co-Teaching}

\author{
Katharine A. Keenan and Darwin H. Tsen \\ Carthage College
}

\begin{abstract}
This reflection focuses on how the opportunity to co-teach across disciplines illuminates the interconnections between literary criticism and ethnographic methodology. We discuss the value of walking as a way of knowing and of creative genres as modes of representation. Through the class's final project, a multimedia map of Kenosha, we see the benefits of a combined literary and ethnographic approach in our students' rigorously observed and sensitively rendered presentations.
\end{abstract}

Keywords: student research experience, humanities, Urban space, walking, poetics, ethnography, post-industrial, local history

\section{Introduction}

With the students piled back on the city bus for their ride back to campus, I released a satisfied sigh. This first excursion of my January term "Ethnography of Kenosha" course bodes well for a good semester. This urban methods course looks closely at Kenosha, Wisconsin, its languishing downtown, dismantled auto plant and funny artistic energy. Through the city's narrative of post-industrial reinvention and eight-cylinder thrust toward creative and leisure economies we examine the significance of urban place-making. Having designed and taught the course twice before, I have typically focused on how to study people and place. This year, however, I am joined by a new coteacher, Dr. Darwin Tsen, a colleague in Modern Languages and Asian Studies. Together, we have reshaped the course into an active and experiential contemplation on knowing and representing place.

This reflection focuses on how the opportunity to co-teach across disciplines illuminates the interconnections between literary criticism and ethnographic methodology. We discuss the value of walking as a way of knowing and of creative genres as modes of representation. Through the class's final project, a multimedia map of Kenosha, we see the benefits of a combined literary and ethnographic approach in our students' rigorously observed and sensitively rendered presentations.

\section{Poetics and Perambulations - Katharine's Reflections}

During the planning process, Darwin and I sought guests with unique relationships to place, and quickly realized they all held walking in common as their way of engaging with and shaping their community: A panel of political activists who canvass Kenosha neighbourhoods on foot; two gallery owners who are invested in creating a walkable arts district, and our college's poet-in-residence, Rick Meier, who reconstructs poems from nature walks. We decided we would craft the class intentionally around walking as a method for both research and representation.

Walking, though not much discussed in methodological tomes, is an essential tool of ethnographic research. Exploring on foot, at ground level, predicates any effort at census taking, observations of public life, or mapping. Low (2005), describes three walking methods in her work on urban parks. The first, embedded in her practice of 
participant observation, is Behavioural Mapping, in which description of the daily activities at a site is used to construct maps of the spatial and temporal boundaries of public behaviour. Low's field notes (2000) also contain detailed descriptions of her own route and movements through a space, including her feelings of comfort and discomfort at different sites and times of day. Second, Physical Traces Mapping looks for surface level traces of human activity at a given site-trash, bottles, clothing, and erosion of plantings or grass due to human footpaths. Revisiting the same site each day to see how such traces move and change makes this archaeological approach useful in studying contemporary spatial practices at ever-changing sites. Finally, the Transect $W$ alk is a moving interview during which an informant takes the researcher on a guided walk, pointing out observations and objects of interest, and what they mean to the local community. Lynch (1960) used the same method in his text on urban planning - testing how residents develop "mental maps" of their neighbourhoods, how place is remembered, visualized, made legible and passable in the mind.

We designed our first excursion around Lynch's transect walk method. This initial foray, designed to defamiliarize the student's experience of Kenosha's downtown, started with filing them onto a bus that stops on Carthage's campus. Taking a lengthy journey through the neighbourhoods to the northwest of campus, students commented on how "inefficient" yet "refreshing" the transportation route was: they took extensive observations of the surroundings, as well as quiet notes about the interactive patterns between the riders and the driver. A whole web of interpersonal and community relations in Kenosha, obscured by their accustomed habit with automobiles, unfolded in front of them. Arriving via the route 4 bus at the downtown transportation centre, we led students southward through parking lots and side-streets, avoiding the familiar storefronts on Kenosha's 6th Avenue. Using Lynch's terminology, we primed them to look for landmarks, boundaries and nodes—junctures of pathways and meaning. We stopped for a moment at the new Kenosha Creative Space to hear how the downtown has evolved in recent years, past empty department store buildings, and a newly renovated boutique hotel, toward a simple house on 7th avenue: Orson Welles' birthplace. At each stop we asked them to think about their emotional reactions to place: recollections that define where they are, or the feelings of comfort and discomfort that Jane Jacobs attributes to the design and walkability of urban spaces. Carrying this toolkit, the students were on their own to meander northward, to look anew at the streets we had just crossed. Back in the coffee shop where we reconvened, they sipped on hot chocolate and coffee while mapping their routes and writing reflections.

Not two weeks later, our guest poet, Rick, took the students on a poetry walk, asking them to note their reactions in much the same manner. We walked single file - in silence - down Campus Drive and onto the Lake Michigan beach, past ice floes, through deep January snow, periodically stopping to capture notes about scenery, feelings, and memories. Once again, a familiar stretch of space, in this case the college's shoreline, was transformed by rearranging the modality of our activity: moving together yet alone, connected through a creative endeavour. Henri Lefebvre often talks about the "production of space", and how the creation of space is a process of constant becoming, moulded by the agents and actors involved; as the class walked single-file down the shoreline, each individual immersed in scribbling down a fleeting impression and sensation, we transformed a geographic "edge" in our surroundings into a space of aesthetic productivity. The sight of 30+ individuals wading down the coastline through sand and snow, pen and paper in hand, was unusual enough that our campus security agents took note, and an officer rushed out, tumbling down the snowy hillside to check on us. Inside the classroom, we each read random selections of our jottings aloud, creating a collective, impressionistic poem. Rick suggested that regardless of the purposepoetry or data collection - the transect walk is a mindful observation. When embarking on a walk we remind ourselves to see, to hear. We force ourselves to reside in our pre-reflective experience. We allow, untypically, for our surroundings to rush our senses, rather than blocking them out with layers of wearable tech and streaming content from our smartphones.

Just so, in Walter Benjamin's place-based memoirs, urban wanderings evoke memories, relationships, and art, producing a multi-layered commentary on urban life. "One Way Street," is constructed as a literary transect walk: a tour of Berlin street signs, pamphlets and placards, construction sites, urban buildings, and objects, each evoking a different meditation on solitude, loss, writing, capitalism, German society, history and love. An experimentation of literary form, Benjamin's work is fragmented, indirect, but also revelatory of the many simultaneous lenses through which we experience space, and the ways in which we constantly shift focus as we move along an urban pathway. For Benjamin and later cultural theorists, this is indicative of the fragmented, polysemic experience of urban social life. As we walk along the road, each step along the continuum is a new place with a new present, simultaneously layering on top of and reframing the last.

Poetry communicates obliquely, through feelings and associations associated with word and image. Poetic arrangements challenge the linearity of printed text, just as the poetry walk and subsequent reading disassembled our 
conventional understanding of campus, by cutting unusual paths, segmenting, and then rearranging our observations. Whereas walking as a research exercise seeks to reassemble patterns of use visible only in the drifts and eddies they leave behind. Ethnography is indeed another way of viewing obliquely, though its reconstructions seek to illuminate and make sense of patterns and behaviours rendered invisible through over familiarity, as well as to incorporate emotional associations into a more comprehensive understanding of place. This is a necessary skill for anthropologists, who must cultivate both an insider's and outsider's perspective, and strive to capture the experience of presence. The transect walk, complemented by the poetry walk, helps us do this through the persistence of awareness.

\section{Maps and Musings - Darwin's Reflections}

Let us briefly return to the Fall of 2017 - I had freshly arrived at Carthage College, and was attending the two-day Teaching and Learning Conference where faculty and staff host workshops to discuss pedagogical issues and to implement technology training. On the second day of the event, after hearing Dr. Keenan showcase her communitybased urban ethnography class that took place during the last January term, I felt electrified. I particularly admired how the course seamlessly combines explorations of Kenosha's history, ethnographic and anthropological methods of inquiry, guiding questions regarding one's imagination of place and belonging, as well as a strong emphasis on the student's engagement with the local community through coursework. It was the type of course I might have designed myself, if I weren't primarily committed to teaching modern East Asian languages. Our institution, however, encourages interdisciplinary co-teaching through a course designation called Carthage Symposium. As a new faculty member, I wanted to take advantage of this unique opportunity to share a classroom with a colleague. Moreover, I believed that the interpretation of literature of and by Kenoshans still had something to add to the class. I contacted Katharine to see if she'd be interested in transforming the course into a C-Sym.

In addition to Katharine's usual teaching texts, Kathryn Dudley's moving End of the Line about the 1989 closure of Kenosha's major auto plant and Amy Goldstein's Janesville, a journalistic account of the 2008 economic crisis and its aftershocks in the county just west of Kenosha, I added a collection of poetry and stories by the Kenosha Writers Guild, and a short selection from Thomas Pynchon's Gravity's Rainbow--in which the phrase "The Kenosha Kid" is segmented and reassembled in a series of playful permutations, thus preserving Kenosha's name in the American literary canon. Each genre and text represent space differently and exposes different relationships between people, place and narrative. Each author situates him or herself slightly differently in time and in history, finding different details of significance in the surrounding locale. The readings complemented our own wanderings, calling to our attention how place carries meaning, not only to residents, but to those who wish to describe it and communicate the sense of "being there" to outsiders.

Fast-forward to the end of January 2019, and our co-taught "Ethnography of Kenosha" class had just successfully wrapped. Although the polar vortex of 2019 prevented a public presentation of our findings, as the course initially required, we had an intimate discussion during our last gathering before the school closed due to the weather. Having re-designed the course to incorporate both ethnographic and creative genres, we assigned a "multimedia map" as the final project; teams of students were required to "map" a neighbourhood in Kenosha using two techniques of data collection and two modes of representation.

We were both deeply impressed with the range and thoughtfulness of projects that our students offered. Some drew and wrote poetry, some took photographs to complement interviews, or videoed their movements through a space. One project recorded the ambient sounds of two nearby grocery stores, one Italian and one Mexican, and described the contents of patrons' shopping baskets. Another student wrote songs from his teammates' ethnographic descriptions. While a longer semester might have allowed for richer engagement with theory and history, these maps demonstrated keenly observant and sensitive engagements with people and place.

At the end of the class, the greatest takeaway for me was realizing how intimately close literary and cultural studies truly was to anthropology and ethnography. The methods of the latter provide a lot more structure and discipline to the task of interpretation. Both literary studies (at least of the contemporary, post-New Criticism variety) and anthropology function on a similar methodological assumption. Here is an object (a text, a group of persons, a film, a community etc.) - make sense of it through looking at its particular aspects, connect it to larger historical contexts and forces to discover patterns, induct or deduct a hypothesis about the whole through its parts. Essentially, both disciplines are deeply engaged in managing an object's relations of similarity and difference to larger social, historical, cultural, or political constructs in a scientific manner. With literary studies, though, the emphasis over the last forty years or so has been to choose, debate, and fine-tune the theoretical glue through which one connects one's object to 
the larger outside. It tends to get mired in the theoretical strata of how to interpret that relation, while it lacks a very fixed and steady lexicon when it comes to the actual task of intaking data prior to embarking on the interpretive act.

What I learned about Ethnography and Anthropology while teaching the course alongside Katharine is that these two fields of study are not only equipped with rock-solid theory, but since they have been directly dealing with human subjects for so long, they both use very precise methodological models concerning almost every type of inquiry or pedagogical need. Take, for example, the Transect Walk - it is an extremely effective model of teaching students and researchers how to "absorb" sensory information while being fully aware that one needs to categorize such information through a geographical lens (with nodes, edges, landmarks, and paths to use Lynch's terminology); it combines the affective, sensuous intake of place with the needs of abstract thinking and mapping. The Transect Walk teaches us that no act of passing through the streets is a neutral one - the space is imbued with all sorts of directed activity and histories that culminate into one's sensation in one given moment. Also consider the journalistic Participant Observation. This mode of inquiry, in an ideal world, should be required training for all journalists: every movement, the ebb and flow of the conversation between the interviewer and interviewee is painstakingly documented, assigned a code of action and classified for later interpretation. There is a kind of unrelenting rigor here, something whose analogue in literary studies might be "close reading", but with more axioms to guide one's performance. It would be an invaluable tool for literary scholars to learn - if not only its ethos - and implement as a way of looking at character dialogue in novels, a subcategory too seldomly studied in our discipline. The methodological rigor of the "most humanistic of the social sciences" has really touched and inspired me. The care, the rigor, and the reflective potential of ethnography and anthropology should be more promoted, cherished, and shared in both the humanities and social sciences.

\section{Conclusion}

Our experience illustrates not only the thrilling correspondence of scientific and humanistic approaches to the study of urban space, but also reinforces the argument (present in Anthropology since at least the 1980s) that an object of inquiry is also an object of creation (Clifford \& Marcus, 1986; Latour, 1991). To bring creative and expressive methods into the teaching of ethnographic research is a way of being overt and explicit about our productive enterprise. Poetic expression, creative writing, and the encouragement of the imagination excites and piques students, while also fostering the kind of humane care that we expect of contemporary ethnographers. Indeed, I believe the final projects our students crafted this year were far more ethnographic, and certainly more sensitive, nuanced, and detailed, than anything my students produced in previous years, prior to this experiment in co-teaching.

\section{References}

Benjamin, W. (1978). One-Way Street' in Demetz, P. (ed), Reflections: Essays, Aphorisms, Autobiographical Writings, New York: Schocken.

Clifford, J., \& Marcus, G. eds. (1986). Writing Culture: The Poetics and Politics of Ethnography. Berkeley: University of California Press.

Dudley, K. (1994). The End of The Line, Chicago: University of Chicago Press.

Goldstein, A. (2017). Janesville: An American Story, New York: Simon and Schuster.

Gourdoux, D. (ed) (2017). Undertow: A Collection by the Kenosha Writer's Guild, CreateSpace Independent Publishing Platform.

Latour, B. (1993). We Have Never Been Modern, (Porter, C. trans.), Cambridge, MA: Harvard University Press.

Lefebvre, H. (1991). The Production of Space, (Nicholson-Smith, D., trans), Malden, MA: Blackwell Publishing.

Low, S. (2000). On the Plaza: The Politics of Public Space and Culture. Austin: University of Texas Press.

Low, S., Taplin, D., \& Scheld, S. (2005). Retbinking Urban Parks: Public Space and Cultural Diversity. Austin:

University of Texas Press 
Lynch, K. (1960). Image of the City, Boston: Harvard-MIT Joint Center for Urban Studies Series.

Meier, R. (2012). In the Pure Block of the Whole Imaginary, Oakland, CA: Omnidawn.

Pynchon, T. (1973). Gravity's Rainbow, New York: Penguin Books. 